\title{
Rooting response of Prunus domestica L. microshoots in the presence of phytoactive medium supplements
}

\author{
Alina Wiszniewska ${ }^{1} \cdot$ Barbara Nowak $^{1}$ - Anna Kołton ${ }^{1} \cdot$ Ewa Sitek $^{1}$. \\ Krzysztof Grabski $^{2} \cdot$ Michał Dziurka $^{3}$ - Olga Długosz-Grochowska ${ }^{1}$. \\ Kinga Dziurka ${ }^{3} \cdot$ Zbigniew Tukaj $^{2}$
}

Received: 31 July 2015/Accepted: 27 December 2015/Published online: 2 January 2016

(C) The Author(s) 2016. This article is published with open access at Springerlink.com

\begin{abstract}
The study aimed at evaluating the response of common plum (Prunus domestica L.) microshoots during in vitro rooting in the presence of two phytoactive medium supplements, i.e. a dialyzate of pineapple pulp and a conditioned medium containing green algae Desmodesmus subspicatus exudates. Rooting efficiency was evaluated after 4 weeks of culture. During the root induction phase the content of phenolic compounds in shoot bases was determined and anatomical studies were conducted. Medium supplements were analyzed for the content of carbohydrates and phenolic acids. Both supplements were efficient in rooting induction of shoots of a difficult-to-root cultivar 'Węgierka Zwykła'. Medium supplementation allowed a significant reduction in the exogenous auxin content required for rooting. The highest rooting efficiencies on supplemented media were 28.9 and $27.8 \%$, in comparison with $33.3 \%$ obtained in the control medium with doubled concentration of exogenous auxins. In the easy-to-root plum cultivar 'Węgierka Dąbrowicka' the rooting rate was slightly reduced in the presence of pineapple dialyzate, while in the presence of algal conditioned medium
\end{abstract}

Electronic supplementary material The online version of this article (doi:10.1007/s11240-015-0937-6) contains supplementary material, which is available to authorized users.

Alina Wiszniewska

a.wiszniewska@ogr.ur.krakow.pl

1 Institute of Plant Biology and Biotechnology, Faculty of Biotechnology and Horticulture, University of Agriculture in Kraków, Al. 29 Listopada 54, 31-425 Kraków, Poland

2 Department of Plant Physiology and Biotechnology, Faculty of Biology, University of Gdańsk, ul. Wita Stwosza 59, 80-308 Gdańsk, Poland

3 The Franciszek Górski Institute of Plant Physiology, Polish Academy of Sciences, Niezapominajek 21, 30-239 Kraków, Poland the rooting rate decreased substantially compared with the nonsupplemented medium. Approximately $30 \%$ of 'Węgierka Dąbrowicka' shoots rooted on supplemented auxin-free media. The content of phenolic compounds accumulated in shoot bases during the root induction stage reflected the differences in rooting ability between both plum cultivars, indicating potential stressful conditions of the culture generated by the presence of phytoactive natural supplements. Anatomical study allowed to recognize the mode of dedifferentiation leading to adventitious rhizogenesis in the common plum. The results are discussed in relation to the composition of medium supplements and their potential root-promoting activity.

Keywords Adventitious rhizogenesis - Biostimulators · Common plum $\cdot$ Phenolic compounds

$\begin{array}{ll}\text { Abbreviations } \\ \text { BAP } & \text { 6-Benzylaminopurine } \\ \text { CA } & \text { Caffeic acid } \\ \text { CGA } & \text { Chlorogenic acid } \\ \text { CM } & \text { Conditioned medium } \\ \text { CY } & \text { Cyanidin } \\ \text { D } & \text { Dialyzed pineapple } \\ \text { IAA } & \text { Indole-3-acetic acid } \\ \text { IBA } & \text { Indole-3-butyric acid } \\ \text { QC } & \text { Quercetin } \\ \text { TPC } & \text { Total phenolic content } \\ \text { WPM } & \text { Woody plant medium }\end{array}$

\section{Introduction}

In tissue cultures of numerous woody species the lack of efficient rooting is the main obstacle in obtaining entire plantlets (Auderset et al. 1997; Hou et al. 2010). Since most 
micropropagation protocols depend on successful development of the root system, Davies et al. (1994) considered adventitious rhizogenesis to be basic in modern horticultural production. Therefore numerous studies are focused on mechanisms that control adventitious root formation, as well as on elaboration of novel, efficient rooting protocols and techniques (Naija et al. 2008; De Klerk et al. 2011; Leva 2011; Sarropoulou et al. 2013). In recent years the European Commission imposed restrictions on the use of chemicals, including auxins, in plant production. Therefore, searching for root-promoting substances and exploitation of natural biostimulators is one of strategies aimed at improving the rooting efficiency with a simultaneous reduction of the use of exogenous auxins (Arthur et al. 2004; Pacholczak et al. 2012a, b; Montero-Calasanz et al. 2013). The application of natural products during commercial rooting may also limit the losses caused by poor quality of the root system or of the shoot, caused by auxin used in the rooting treatment (De Klerk et al. 1999; Kakani et al. 2009).

Root-promoting substances may contain purified active compounds, but also either defined or undefined mixtures of organic supplements, such as algae extracts, plant extracts and cell exudates, as well as microbial components (Serna et al. 2012; Pacholczak et al. 2012a, b; Stirk et al. 2014). Studies confirmed that natural biopreparations may stimulate the development of plant organs, with a limited influence on the environment (Pacholczak et al. 2012a, b; Okunlola and Ofuya 2013). Therefore, such products provide an alternative to synthetic agrochemicals used in crop production (Saxena and Pandey 2001). Recently, the biological activity of natural additives was evaluated in tissue cultures of numerous plant species, including agricultural crops such as pea (Molnar and Ördög 2005) and date palm (Al-Khayri 2011), medicinal plants (Amin et al. 2009) and ornamentals (Kaur and Bhutani 2012; Wiszniewska et al. 2013). It has been proved that the use of phytoactive medium supplements promotes organogenesis, differentiation of cultured tissues, as well as the ability of the obtained microplantlets to acclimatize. Media enriched with organic additives are proposed to be applied especially in the cultures of in vitro recalcitrant plants to improve regeneration processes (Neumann et al. 2009).

Rooting difficulties occur in micropropagation of plants belonging to Prunus genus (Gonzales Padilla et al. 2003; Štefančič et al. 2005; Tereso et al. 2008). Shoots of both fruit-bearing and ornamental species are considerably easily multiplicated in vitro (Nowak and Miczyński 2002; Kalinina and Brown 2007; Petri and Scorza 2010), while root formation remains problematic. Particularly, in the common plum (Prunus domestica L.), a commercially important stone fruit tree, the rooting efficiency is low, despite the attempts directed towards higher effectiveness of the process (choice of the auxin, root induction procedure, one- or multi-step culturing, treatment duration etc.) (Gonzales Padilla et al. 2003; Tian et al. 2007). Despite numerous studies on regeneration potential of the common plum, the process of adventitious rhizogenesis itself has not been investigated extensively in this important fruit tree. The evaluation of anatomical and biochemical response connected with adventitious rhizogenesis could enable further rooting improvements in the plum, as it was proven in other woody plants (McDonald and Wynne 2003; Naija et al. 2008). Phenolic compounds are considered as woundingrelated substances that promote the rooting ability and markers of a well defined physiological state favorable to adventitious root formation (Curir et al. 1990; De Klerk et al. 1999). However, to date there are no reports available on the accumulation of phenolics during adventitious rhizogenesis in the common plum.

The aim of our study was to evaluate the root-promoting activity of two phytoactive organic supplements, i.e. pineapple pulp dialyzate and conditioned medium containing green algae exudates, during in vitro rooting of the common plum (Prunus domestica L.). Both additives examined were recently found to promote rooting in woody Daphne species (Wiszniewska et al. 2013). Therefore, the current study was designed to assess their suitability as potential rooting stimulators in woody plants. The effect of these supplements was also tested in relation to anatomical processes and biochemical response during rhizogenesis, namely the accumulation of phenolics. Another purpose was to develop a protocol enabling the reduction of exogenous auxin level used for in vitro rooting of the plum.

\section{Materials and methods}

\section{Plant material}

In vitro shoots of two Polish plum cultivars, 'Węgierka Zwykła' (referred further as WZ) and 'Węgierka Dąbrowicka' (referred further as WD), were used as the plant material. Shoots from stabilized cultures were multiplicated on solid MS medium (Murashige and Skoog 1962) containing $2.22 \mu \mathrm{M}$ 6-benzylaminopurine (BAP) and $0.49 \mu \mathrm{M}$ indole-3-butyric acid (IBA) at $\mathrm{pH}=5.5$ (Małodobry 1986) for 5 weeks. The medium contained $0.8 \%$ Oxoid agar and $30 \mathrm{~g} / 1$ sucrose, and was autoclaved for $20 \mathrm{~min}$ at $0.1 \mathrm{MPa}$ and $121{ }^{\circ} \mathrm{C}$. Cultures were maintained in a growth chamber under a 16 -h photoperiod (irradiance $80 \mu \mathrm{mol} \mathrm{m} \mathrm{m}^{-2}$ ) at $24 \pm 2{ }^{\circ} \mathrm{C}$.

\section{Rooting protocol}

Healthy 15-20 mm-long tip shoots (bearing an apical meristem) were selected for rooting (Fig. 1). Root 
induction stage was conducted for 7 days on several culture media based on woody plant medium (WPM) formulation (Lloyd and McCown 1981) and containing: (1) $25.54 \mu \mathrm{M}$ indole-3-acetic acid (IAA) and $9.84 \mu \mathrm{M}$ IBA (acc. to Małodobry 1986, control treatment, $\mathrm{S}_{\mathrm{C}}$ ); (2) 1/2 auxin concentration (12.77 $\mu \mathrm{M}$ IAA and $4.92 \mu \mathrm{M}$ IBA) (1/ $2 \mathrm{~S}_{\mathrm{C}}$ ); (3) $1 / 2$ auxin concentration $(12.77 \mu \mathrm{M}$ IAA and $4.92 \mu \mathrm{M} \mathrm{IBA}$ ) and $10 \mathrm{ml} / 1$ of dialyzed pineapple pulp (low-molecular-weight fraction, $<500 \mathrm{Da})\left(\mathrm{S}_{\mathrm{D}}\right)$; (4) $1 / 2$ auxin concentration $(12.77 \mu \mathrm{M}$ IAA and $4.92 \mu \mathrm{M}$ IBA) and $10 \%(\mathrm{v} / \mathrm{v})$ of conditioned medium obtained from the green algae culture (conditioned medium, $\mathrm{CM})\left(\mathrm{S}_{\mathrm{CM}}\right) ;(5)$ $10 \mathrm{ml} / \mathrm{l}$ of dialyzed pineapple pulp, with no exogenous auxins $\left(0 \mathrm{~S}_{\mathrm{D}}\right)$; and (6) $10 \%(\mathrm{v} / \mathrm{v})$ of conditioned medium obtained from the green algae culture, with no exogenous auxins $\left(0 \mathrm{~S}_{\mathrm{CM}}\right)$. Additionally, a trial with the medium without auxins and supplements was conducted, but no rooting response occurred. This medium was not included in an experimental scheme. All media contained $0.8 \%$ Oxoid agar and $30 \mathrm{~g} / \mathrm{l}$ sucrose and were autoclaved for $20 \mathrm{~min}$ at $0.1 \mathrm{MPa}$ and $121{ }^{\circ} \mathrm{C}$. Pineapple pulp was prepared according to Kitsaki et al. (2004). The dialyzate of pineapple pulp and conditioned medium after the green alga Desmodesmus subspicatus culture (CM) were produced as described earlier (Grabski and Tukaj 2008; Wiszniewska et al. 2013). After 7 days the shoots were transferred to a hormone-free MS medium for root elongation. Root development was monitored during 4 weeks in 1-week intervals and the effectiveness of rooting was evaluated. Data were collected on the number of rooted explants (rooting percentage), the number of developed roots per explant and the length of roots. Stem bases were examined for the way of root development (acrobasal or basal), as well as for callus formation. During the whole rooting experiment the cultures were kept in a growth chamber under a 16-h photoperiod (irradiance $80 \mu \mathrm{mol} \mathrm{m}{ }^{-2} \mathrm{~s}^{-1}$ ) at $24 \pm 2{ }^{\circ} \mathrm{C}$.

\section{Phenolic profile determination}

Concentration of phenols was determined in $5 \mathrm{~mm}$-long basal parts of microcuttings (rooting zone) that were collected

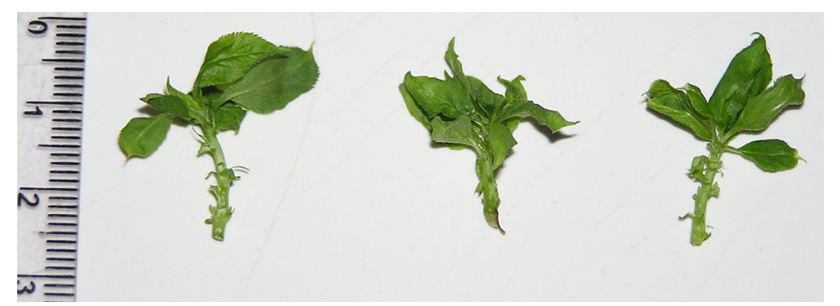

Fig. 1 Morphology of representative Prunus domestica L. microshoots subjected to rooting treatment directly before the root induction stage $(0 \mathrm{~h})$ and after 7 days. The samples collected were weighted and stored frozen at $-20{ }^{\circ} \mathrm{C}$ until analysis. Phenolic compounds (total phenols, phenylpropanoids, flavonols and anthocyanins) were determined using an UV/VIS Hitachi U-2900 spectrophotometer according to Fukumoto and Mazza (2000). The content of phenolic compounds was expressed in $\mathrm{mg}$ of respective standard equivalents [chlorogenic acid (CGA) for total phenolic content (TPC), caffeic acid (CA) for phenylpropanoids, quercetin $(\mathrm{QC})$ for flavonols, and cyanidin $(\mathrm{CY})$ for anthocyanins] per $100 \mathrm{~g}$ of fresh tissue weight.

\section{Anatomical studies}

Anatomical observations were conducted on $5 \mathrm{~mm}$ long basal segments of rooted shoots after cultivation on all rooting media for 7 days for both WZ and WD cultivars. Shoots of WD rooted on $S_{C M}$ were sampled also on the 5th day and on SD medium on the 6th day; the control shoots were taken before rooting. Five shoots randomly chosen for each treatment were fixed in Carnoy's solution followed by embedding in paraffin. After dehydration in a series of ethanol, transverse and longitudinal cross-sections, 8-10 $\mu \mathrm{m}$ thick, were stained with alcian blue and Heidenheim hematoxylin (Filutowicz and Kużdowicz 1951). The specimens were analyzed in an Axio Imager M2 microscope (Zeiss) using Axiovision software.

\section{Characterization of pineapple dialyzate}

Total sugars in the pineapple dialyzate were estimated using a PR-100 Palette (ATAGO Co. Ltd. Japan) digital refractometer. Soluble sugars were analyzed as reported by Pociecha and Dziurka (2015) with modifications, using an HPLC Agilent 1200 system equipped with a degasser, a binary pump, an automated liquid sampler and a thermostated column compartment (Agilent, Germany) and an ESA Coulochem II electrochemical detector with a 5040 Analytical Cell (ESA, USA) with an nalogue-to-digital converter. Phenolic acids were analysed on a UHPLC system (Agilent Infinity 1260) equipped with a binary pump, an autosampler and a fluorescence detector (FLD).

\section{Characterization of conditioned medium}

Algal conditioned medium was tested for total sugar content and for the presence of phenolic acids. Total sugars were estimated using a PR-100 Palette (ATAGO Co. Ltd. Japan) digital refractometer. Phenolic acids in CM samples were determined by means of an HPLC (Shimadzu, Japan) system equipped with an LC-20AD pump, a DGU-20A5 degasser, a CTO-10AS VP column oven and an SPD-M20 A diode array detector. 


\section{Experimental design and statistics}

The experiments were repeated twice, and at least 20 microcuttings per treatment were used for rooting in a single replicate. For determination of phenolic profile and anatomical studies an additional replicate was established, covering a 7-day long root induction stage only. At least three randomly chosen shoot bases per treatment were used for extraction and measurements. The data collected were subjected to either one- or two-way ANOVA analysis using STATISTICA 10.0 software (StatSoft inc., Tulsa, OK, USA). Duncan's test was used to study the differences between treatments at $P<0.05$.

\section{Results}

\section{Rooting efficiency}

Adventitious rooting in 'Węgierka Dąbrowicka' was an effective process. In the control treatment (medium $\mathrm{S}_{\mathrm{C}}$ ) rooting rate reached $73.4 \%$ (Table 1 ). When exogenous auxin content was reduced by half, all explanted shoots produced roots during 3 weeks of culture (Online Resource 1). Root primordia were yet visible on shoots transferred from the induction medium onto the elongation one. On the media with a reduced content of auxins and phytoactive supplement, the rooting rate was lower than on the nonsupplemented medium variant (Table 1). Rooting percentage in the presence of dialyzed pineapple pulp (medium $\mathrm{S}_{\mathrm{D}}$ ) was reduced to $89 \%$; while in the presence of algal exudates $\left(\mathrm{S}_{\mathrm{CM}}\right)$ it decreased by half in comparison with the non-supplemented medium $\left(1 / 2 \mathrm{~S}_{\mathrm{C}}\right)$, to nearly $50 \%$ (Table 1). WD shoots produced roots also after the induction on media without exogenous auxins, supplemented only with tested organic supplements. The rooting efficiency reached approximately $30 \%$ on the medium containing either dialyzed pineapple pulp $\left(0 \mathrm{~S}_{\mathrm{D}}\right)$ or conditioned medium $\left(0 \mathrm{~S}_{\mathrm{CM}}\right)$ (Table 1$)$.

The mean number of roots/explant was the highest on medium $1 / 2 \mathrm{~S}_{\mathrm{C}}$ and its variant containing pineapple dialyzate (4.7 and 4.3, respectively; differences statistically insignificant) (Table 1). On shoots from the control $\left(\mathrm{S}_{\mathrm{C}}\right)$ and auxincontaining medium with $\mathrm{CM}\left(\mathrm{S}_{\mathrm{CM}}\right), 3.7$ and 3.3 roots/shoot were formed (Table 1) on the average. Shoots rooted in auxin-free media $\left(0 \mathrm{~S}_{\mathrm{D}}\right.$ and $\left.0 \mathrm{~S}_{\mathrm{CM}}\right)$ produced approximately 2 roots/explant. The growth of roots was the fastest on the medium with the reduced auxin content and with no supplements. After 4 weeks mean root length was $89.2 \mathrm{~mm}$ (Table 1). Shorter roots, 65.1-66.3 mm long, developed on both media containing pineapple dialyzate $\left(0 \mathrm{~S}_{\mathrm{D}}\right.$ and $\left.\mathrm{S}_{\mathrm{D}}\right)$, irrespective of the presence of exogenous auxins (Table 1). Roots produced on media containing algal $\mathrm{CM}\left(0 \mathrm{~S}_{\mathrm{CM}}\right.$ and
$\left.\mathrm{S}_{\mathrm{CM}}\right)$ were as long as those from the control medium $\left(\mathrm{S}_{\mathrm{C}}\right)$ (Table 1). On media $S_{C}$ and $S_{D}$, root systems with lateral roots developed during 4 weeks of culture (Fig. 2a). During successive weeks of culture on $\mathrm{S}_{\mathrm{D}}$ medium $62 \%$ of plantlets formed new root primordia (data not shown). After 4 weeks of culture $21 \%$ of roots produced in $1 / 2 \mathrm{~S}_{\mathrm{C}}$ medium developed 1-3 mm long lateral roots. On the medium containing auxins and algal exudates $\left(\mathrm{S}_{\mathrm{CM}}\right)$ single adventitious roots developed with short $(<2 \mathrm{~mm})$ lateral roots. Irrespective of the medium adventitious roots developed basally, directly from the stem (Fig. 2a).

The second plum cultivar 'Węgierka Zwykła' rooted poorly in applied culture conditions. After the induction on the control medium $\left(\mathrm{S}_{\mathrm{C}}\right)$ the percentage of rooted shoots reached $33.3 \%$ (Table 1). On the non-supplemented medium with a reduced content of exogenous auxins $\left(1 / 2 \mathrm{~S}_{\mathrm{C}}\right)$ the rooting rate decreased to $16.5 \%$ (Table 1). In the presence of reduced auxin content and either pineapple dialyzate $\left(\mathrm{S}_{\mathrm{D}}\right)$ or algal conditioned medium $\left(\mathrm{S}_{\mathrm{CM}}\right)$ the rooting was promoted as compared to the non-supplemented medium (1/ $2 \mathrm{~S}_{\mathrm{C}}$ ) and its efficiency reached 28.9 and $27.4 \%$, respectively (Table 1 ). On media without exogenous auxins and supplemented with tested additives the rooting was either poor $\left(8.5 \%\right.$ on $0 \mathrm{~S}_{\mathrm{CM}}$ ) or unsuccessful (no response on $0 \mathrm{~S}_{\mathrm{D}}$ ) (Table 1). The highest number of developed roots per explant amounted to three on the medium enriched with algal $\mathrm{CM}\left(\mathrm{S}_{\mathrm{CM}}\right)$ (Table 1). On the remaining media the mean number of roots did not exceed two roots/explant (Table 1). The longest roots were produced after the induction on both media supplemented with algal $\mathrm{CM}\left(0 \mathrm{~S}_{\mathrm{CM}}\right.$ and $\mathrm{S}_{\mathrm{CM}}$ ) (67.0 and $64.3 \mathrm{~mm}$, respectively) (Table 1). The shortest roots (mean: $25.3 \mathrm{~mm}$ long) developed on a nonsupplemented medium with a reduced auxin content $\left(1 / 2 \mathrm{~S}_{\mathrm{C}}\right)$. On $14 \%$ of adventitious roots developed on $\mathrm{S}_{\mathrm{C}}$ medium short, 1-mm long, lateral roots were visible after 4 weeks of culture. However, the complete root system has not been formed. Similarly to WD, adventitious roots developed basally, directly from the stem (Fig. 2b).

Kinetics of adventitious rooting was monitored on the basis of changes in rooting percentage, number of developed roots per microshoot and root length in subsequent weeks of root elongation stage (Online Resource 1). Overall, the influence of culture medium described after 4 weeks was apparent from the beginning of this stage of the experiment. From the 3 weeks rooting percentage and mean number of roots/explant were rather constant, while root length was increasing throughout the culture period (Online Resource 1).

\section{Callus formation and morphology of rooted microcuttings}

During the root elongation stage of the experiment a callus was formed in the basal part of shoots. In both plum 
Table 1 Effect of induction medium on rooting process of Prunus domestica L. 'Węgierka Dąbrowicka' and 'Węgierka Zwykła' microshoots after 4 weeks of culture

\begin{tabular}{|c|c|c|c|c|c|c|c|}
\hline \multicolumn{3}{|c|}{ Medium } & \multirow{2}{*}{$\begin{array}{l}\text { Rooting } \\
(\%)\end{array}$} & \multirow{2}{*}{$\begin{array}{l}\text { No. roots/ } \\
\text { shoot }\end{array}$} & \multirow{2}{*}{$\begin{array}{l}\text { Root length } \\
(\mathrm{mm})\end{array}$} & \multirow{2}{*}{$\begin{array}{l}\text { Callusing shoot } \\
\text { bases }(\%)\end{array}$} & \multirow{2}{*}{$\begin{array}{l}\text { Callus diameter } \\
(\mathrm{mm})\end{array}$} \\
\hline Code & Auxin $(\mu \mathrm{M})$ & $\begin{array}{l}\text { Organic } \\
\text { additive }\end{array}$ & & & & & \\
\hline \multicolumn{8}{|c|}{ 'Wegierka Dabrowicka' } \\
\hline$S_{C}^{1}$ & $28.54 \mathrm{IAA}^{2}, 9.84 \mathrm{IBA}^{3}$ & - & $73.4 \pm 2.6 \mathrm{c}$ & $3.6 \pm 0.2 b$ & $45.8 \pm 2.1 \mathrm{c}$ & $83.3 \pm 6.4 b$ & $2.7 \pm 0.7 \mathrm{a}$ \\
\hline $1 / 2 \mathrm{~S}_{\mathrm{C}}$ & $1 / 2 S_{C}$ & - & $100.0 \pm 0 \mathrm{a}$ & $4.7 \pm 0.2 \mathrm{a}$ & $89.2 \pm 4.4 \mathrm{a}$ & $29.3 \pm 1.5 \mathrm{~d}$ & $2.0 \pm 1.1 \mathrm{a}$ \\
\hline $\mathrm{S}_{\mathrm{D}}$ & $1 / 2 S_{C}$ & $10 \mathrm{ml} / 1 \mathrm{D}^{4}$ & $89.1 \pm 4.1 b$ & $4.3 \pm 0.3 \mathrm{a}$ & $66.3 \pm 1.4 \mathrm{~b}$ & $58.7 \pm 2.9 \mathrm{c}$ & $2.4 \pm 0.8 \mathrm{a}$ \\
\hline $\mathrm{S}_{\mathrm{CM}}$ & $1 / 2 S_{C}$ & $10 \% \mathrm{CM}^{5}$ & $49.8 \pm 4.2 \mathrm{~d}$ & $3.3 \pm 0.3 b$ & $43.3 \pm 2.4 \mathrm{c}$ & $100 \pm 0 \mathrm{a}$ & $2.6 \pm 1.2 \mathrm{a}$ \\
\hline $0 S_{\mathrm{D}}$ & - & $10 \mathrm{ml} / 1 \mathrm{D}$ & $31.4 \pm 1.6 \mathrm{e}$ & $2.2 \pm 0.2 \mathrm{c}$ & $65.1 \pm 3.3 \mathrm{~b}$ & $74.8 \pm 3.7 b$ & $3.1 \pm 0.6 \mathrm{a}$ \\
\hline $0 \mathrm{~S}_{\mathrm{CM}}$ & - & $10 \% \mathrm{CM}$ & $29.8 \pm 1.5 \mathrm{e}$ & $1.8 \pm 0.2 \mathrm{c}$ & $47.1 \pm 2.4 \mathrm{c}$ & $61.8 \pm 3.0 \mathrm{c}$ & $2.9 \pm 0.7 \mathrm{a}$ \\
\hline \multicolumn{8}{|c|}{ 'Wegierka Zwykta' } \\
\hline $\mathrm{S}_{\mathrm{C}}$ & 28.54 IAA, 9.84 IBA & - & $33.3 \pm 4.3 \mathrm{a}$ & $1.7 \pm 0.6 \mathrm{~b}$ & $54.5 \pm 4.2 b$ & $100 \pm 0 \mathrm{a}$ & $3.8 \pm 0.3 \mathrm{a}$ \\
\hline $1 / 2 \mathrm{~S}_{\mathrm{C}}$ & $1 / 2 S_{C}$ & - & $16.5 \pm 0.8 b$ & $1.5 \pm 0.1 \mathrm{~b}$ & $25.3 \pm 1.3 \mathrm{~d}$ & $22.8 \pm 1.2 \mathrm{e}$ & $2.0 \pm 0.2 \mathrm{~b}$ \\
\hline$S_{D}$ & $1 / 2 S_{C}$ & $10 \mathrm{ml} / 1 \mathrm{D}$ & $28.9 \pm 2.8 \mathrm{a}$ & $1.5 \pm 0.3 \mathrm{~b}$ & $46.5 \pm 3.6 \mathrm{c}$ & $61.8 \pm 3.1 \mathrm{c}$ & $1.9 \pm 0.6 b$ \\
\hline $\mathrm{S}_{\mathrm{CM}}$ & $1 / 2 S_{C}$ & $10 \% \mathrm{CM}$ & $27.4 \pm 2.4 \mathrm{a}$ & $3.0 \pm 0.4 \mathrm{a}$ & $64.3 \pm 5.1 \mathrm{a}$ & $87.5 \pm 5.3 b$ & $2.0 \pm 0.5 b$ \\
\hline $0 S_{D}$ & - & $10 \mathrm{ml} / 1 \mathrm{D}$ & Od & $0 \mathrm{c}$ & $0 \mathrm{e}$ & $8.3 \pm 0.4 f$ & $1.5 \pm 0.4 b$ \\
\hline $0 \mathrm{~S}_{\mathrm{CM}}$ & - & $10 \% \mathrm{CM}$ & $8.3 \pm 0.4 c$ & $1.0 \pm 0.1 \mathrm{~b}$ & $67.0 \pm 3.4 \mathrm{a}$ & $33.3 \pm 1.7 \mathrm{~d}$ & $1.0 \pm 0.8 b$ \\
\hline
\end{tabular}

Values represent mean \pm SE. For each cultivar means followed by different letters within columns are significantly different at $P<0.05$

${ }^{1} \mathrm{~S}_{\mathrm{C}}$ control medium acc. to Małodobry (1986); ${ }^{2}$ indole-3-acetic acid, ${ }^{3}$ indole-3-butyric acid, ${ }^{4} \mathrm{D}$, dialyzed pineapple pulp, ${ }^{5} \mathrm{CM}$, conditioned medium containing exudates of green alga Desmodesmus subspicatus

cultivars callus formation occurred regardless of the treatment applied (Table 1). In the case of WD all media containing phytoactive supplements (both in the presence and in the absence of exogenous auxins: $\mathrm{S}_{\mathrm{D}}, \mathrm{S}_{\mathrm{CM}}, 0 \mathrm{~S}_{\mathrm{D}}$ and $0 \mathrm{~S}_{\mathrm{CM}}$ ), as well as the control medium with high auxin content $\left(\mathrm{S}_{\mathrm{C}}\right)$ promoted callusing of the shoot bases. The lowest frequency of callusing shoots, amounting to $29.3 \%$, was found on the non-supplemented medium with a reduced auxin content $\left(1 / 2 \mathrm{~S}_{\mathrm{C}}\right)$ (Table 1$)$. On the media containing exogenous auxins the size of callus clusters ranged from 2.7 to $2.0 \mathrm{~mm}$, while on the auxin-free supplemented media the diameter of callus clusters on the average reached $3.2 \mathrm{~mm}$ (Table 1).

In WZ shoots rooted on the media containing exogenous auxins $\left(1 / 2 \mathrm{~S}_{\mathrm{C}}, \mathrm{S}_{\mathrm{C}}, \mathrm{S}_{\mathrm{D}}\right.$ and $\left.\mathrm{S}_{\mathrm{CM}}\right)$ callus was formed on $22.8-100 \%$ of shoots (Table 1). Low callusing level was also noted on shoots rooted on supplemented auxin-free media, $0 \mathrm{~S}_{\mathrm{CM}}$ and $0 \mathrm{~S}_{\mathrm{D}}$ (24.8 and $21.1 \%$, respectively) (Table 1). The mean diameter of callus aggregates ranged from 1.5 to $3.8 \mathrm{~mm}$ (Table 1). In WZ, larger aggregates were formed on shoots induced on control medium $S_{C}$, smaller ones on the remaining media (Table 1). In both plum cultivars no adventitious roots emerged from the callus tissue.

'Węgierka Dąbrowicka' shoots showed no symptoms of aging or morphological abnormalities during the culture. Shoots were properly colored, with numerous large leaves. In contrast, in 'Węgierka Zwykła' shoots rooted on media containing exogenous auxins the convolution of upper leaves occurred during the first two wk of root elongation stage. This phenomenon receded during the third wk of the elongation stage in shoots derived from supplemented media with a reduced auxin content $\left(1 / 2 \mathrm{~S}_{\mathrm{C}}, \mathrm{S}_{\mathrm{D}}\right.$, and $\left.\mathrm{S}_{\mathrm{CM}}\right)$, and after 4 weeks on control medium with high auxin content $\left(\mathrm{S}_{\mathrm{C}}\right)$. Nevertheless, 4 weeks old $\mathrm{WZ}$ microcuttings exhibited symptoms of senescence, i.e. yellowish and shedding leaves. The formation of adventitious buds on the shoot base was observed occasionally.

\section{The content of phenolic compounds at the beginning and at the end of root induction stage}

The level of total phenolic compounds (TPC) before the root induction stage was the same in both plum cultivars, and significantly lower than after 7 days of induction on all media examined (Table 2). The content of phenylpropanoids also did not differ between both cultivars before root induction. However, WZ plum contained significantly higher amounts of flavonols and anthocyanins than did WD (Table 2).

After 7 days of root induction on all tested media phenolic compounds were accumulated in shoot bases. According to two-way ANOVA, in non-supplemented media the level of phenolic compounds usually did not differ between the plum cultivars (Fig. 2). The exceptions were higher contents of phenylpropanoids in WD on the 

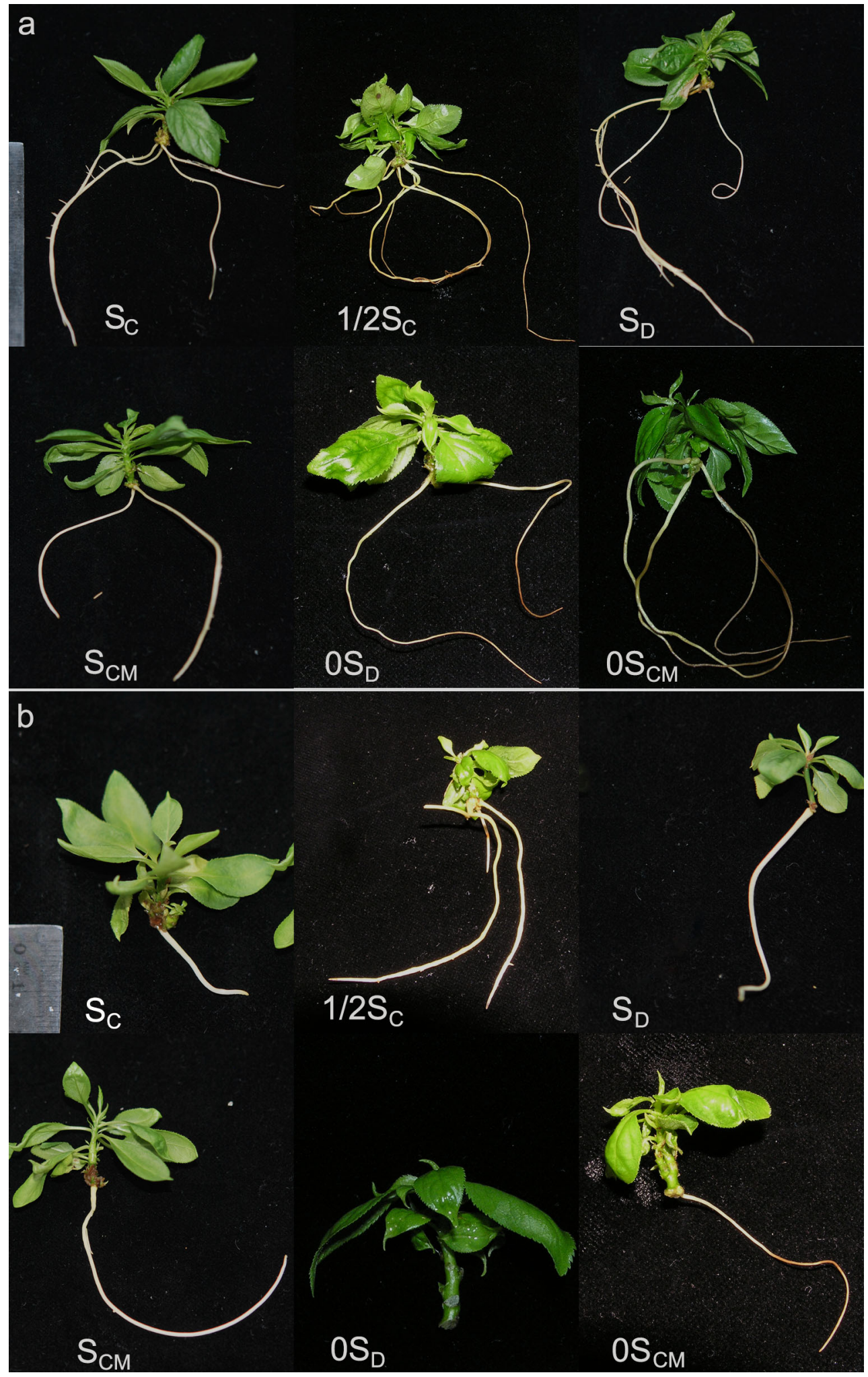

Fig. 2 Adventitious rhizogenesis of Prunus domestica L. microcuttings on six tested media $\left(\mathrm{S}_{\mathrm{C}}, 1 / 2 \mathrm{~S}_{\mathrm{C}}, \mathrm{S}_{\mathrm{D}}, \mathrm{S}_{\mathrm{CM}}, 0 \mathrm{~S}_{\mathrm{D}}, 0 \mathrm{~S}_{\mathrm{CM}}\right)$. a ${ }^{\prime} \mathrm{Węgierka}$ Dąbrowicka' and b 'Węgierka Zwykła' 
control medium and anthocyanins in cv. WZ on the medium with a reduced auxin concentration (Fig. 3). The phytoactive supplements influenced the accumulation of phenolic compounds. In the case of total phenolic content WZ and WD responded similarly on media containing pineapple dialyzate $\left(\mathrm{S}_{\mathrm{D}}\right.$ and $\left.0 \mathrm{~S}_{\mathrm{D}}\right)$. In media containing algal exudates WD plum accumulated higher amounts of phenolic compounds than WZ (Fig. 3). The concentration of phenylpropanoids and flavonols was also higher in WD than in WZ, apart from the medium $0 \mathrm{~S}_{\mathrm{CM}}$, where both cultivars accumulated similar amounts of these compounds (Fig. 3). On the majority of the supplemented media a higher level of anthocyanins was detected in WZ than in $W D$, with the exception of $0 S_{D}$ medium, where anthocyanin levels were equal in both WD and WZ (Fig. 3). Irrespective of the plum cultivar, the highest concentration of total phenolics in shoot bases was observed on the auxin-free medium supplemented with dialyzed pineapple pulp. This additive also promoted accumulation of phenylpropanoids and flavonols in comparison with algal $\mathrm{CM}$, both on the medium with and without exogenous auxins.

\section{Anatomical studies}

The signs of dedifferentiation were present on each of the examined shoots. Areas of dividing cells were noticed or at least cells with a competence to divide (with big nucleus) could be distinguished (Fig. 4a-c). The division activity in the upper parts of the analyzed stems was located in three regions. Cell division took place in the phloem region (phloem parenchyma) forming elongated or irregular meristematic centres which produced numerous cells altering the cortical parenchyma structure (Fig. 4c). Another area in which the cells became activated was cortical parenchyma where usually subepidermal cells divided (Fig. 4b, d). The cells with prominent nuclei and dense cytoplasm were also observed in parenchyma of the core adjacent to the xylem (Fig. 4e) and in the consequence of further divisions the vascular cylinder was interrupted (Fig. 5a). The cell division activity was also noticed alongside shoot cutting edge. In this area the cells dividing tangentially could form an organized layer (Fig. 4f) or, more frequently, create the region of disorganized dividing cells.

The least advanced division activity observed in shoots sampled from the auxin-containing media on the 5th day of induction covered divisions of the core parenchyma cells and some of the phloem. The most advanced dedifferentiation was noticed within phloem-derived meristematic centres (Fig. 5a), where new differentiated xylem cells were observed already after 5 days of rooting WD shoots on $\mathrm{S}_{\mathrm{CM}}$ medium. This structure could be root primordium with differentiated vascular system growing through the cortical parenchyma (Fig. 5a). The same way of root differentiation was observed on WD shoots after 7 days of cultivation on $S_{C}, 1 / 2 S_{C}$ and $S_{D}$ media, both with and without callus formation (Fig. $5 \mathrm{~b}-\mathrm{d}$ ).

\section{Characterization of pineapple pulp}

Total sugars in the pineapple dialyzate amounted to $4.3 \%$. The profile of detected and quantified carbohydrates is given in Table 3. Fructose and glucose monosaccharides prevailed over other compounds, both reaching a concentration of $16.5 \mathrm{mg} / \mathrm{ml}$ of dialyzate (Table 3). Also disaccharides: maltose $(1.4 \mathrm{mg} / \mathrm{ml})$, sucrose $(0.3 \mathrm{mg} / \mathrm{ml})$ and trehalose $(0.002 \mathrm{mg} / \mathrm{ml})$, as well as trisaccharide izomaltotriose $(0.1 \mathrm{mg} / \mathrm{ml})$ were detected. Among fructans, trisaccharide kestose with a concentration of $0.3 \mathrm{mg} / \mathrm{ml}$ was found.

In pineapple dialyzate sixteen phenolic acids were detected and quantified (Table 4). The prevailing compounds were homovanillic acid $(11.1 \mu \mathrm{g} / \mathrm{ml}$ of pineapple pulp), vanillic acid $(4.5 \mu \mathrm{g} / \mathrm{ml})$ and cinnamic acid $(4.5 \mu \mathrm{g} /$ $\mathrm{ml})$. Eight compounds were present in the concentration range $0.9-0.2 \mu \mathrm{g} / \mathrm{ml}$, three in $0.05-0.01 \mu \mathrm{g} / \mathrm{ml}$, and two below $0.01 \mu \mathrm{g} / \mathrm{ml}$ (Table 4).

\section{Characterization of conditioned medium}

Total sugars (extract) in algal CM amounted to $0.2 \%$ and this was regarded as trace amounts. Therefore the detailed carbohydrate profile was not performed. Phenolic acids were not detected in CM samples (Fig. 6).

Table 2 Phenolic profile in Prunus domestica L. 'Węgierka Dąbrowicka' and 'Węgierka Zwykła' microshoots before root induction treatment

\begin{tabular}{llllr}
\hline Cultivar & $\begin{array}{l}\text { Total phenolics (mg } \\
\text { CGA/100 g f.w.) }\end{array}$ & $\begin{array}{l}\text { Phenylpropanoids } \\
\text { (mg CA/100 g f.w) }\end{array}$ & $\begin{array}{l}\text { Flavonols (mg } \\
\text { QC/100 g f.w.) }\end{array}$ & $\begin{array}{l}\text { Anthocyanins (mg } \\
\text { CY/100 g f.w.) }\end{array}$ \\
\hline 'Węgierka Dąbrowicka' & $301.59 \pm 17.5 \mathrm{a}$ & $57.51 \pm 3.8 \mathrm{a}$ & $49.79 \pm 1.1 \mathrm{~b}$ & $9.62 \pm 1.2 \mathrm{~b}$ \\
'Węgierka Zwykła' & $352.46 \pm 19.8 \mathrm{a}$ & $65.34 \pm 5.6 \mathrm{a}$ & $61.55 \pm 1.5 \mathrm{a}$ & $15.45 \pm 0.1 \mathrm{a}$ \\
\hline
\end{tabular}

Values represent mean \pm SE. For each cultivar means followed by different letters within columns are significantly different at $P<0.05$

$C G A$ chlorogenic acid, $C A$ caffeic acid, $Q C$ quercetin, $C Y$ cyanidin 

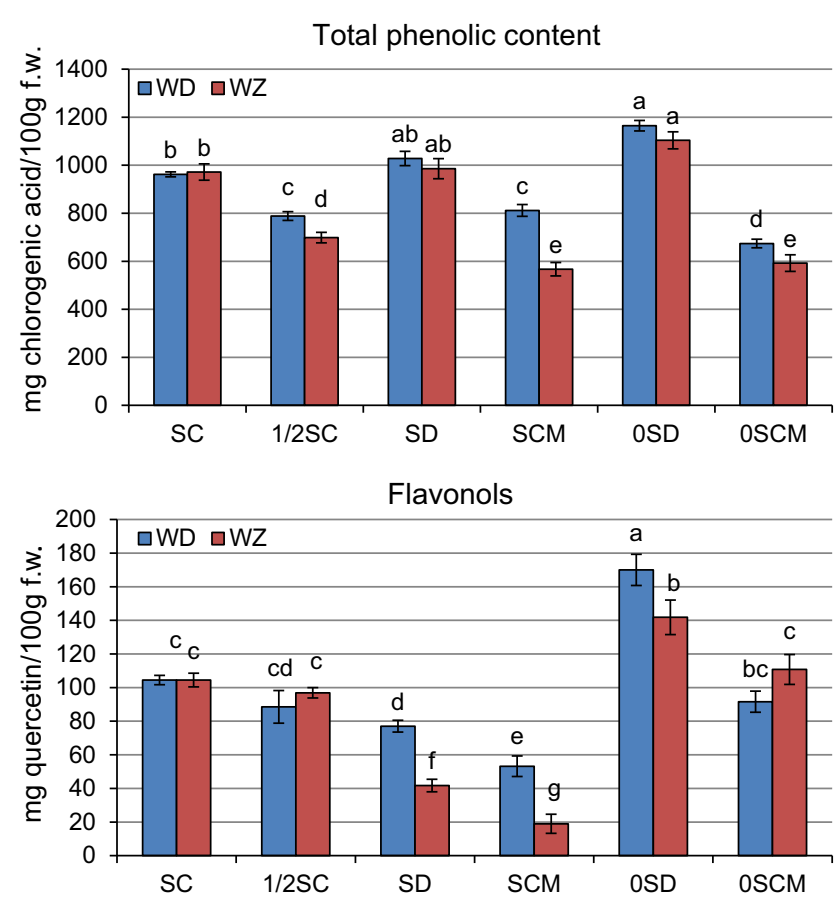

Fig. 3 Effect of root induction medium on phenolic profile in microshoots of 'Węgierka Dąbrowicka'(WD) and 'Węgierka Zwykła' (WZ) after 7 days of root induction phase. Different lowercase letters on each graph indicate means that are statistically different according

\section{Discussion}

Despite effective protocols for shoot development and multiplication, rooting frequency in the common plum is still insufficient (Nowak and Miczyński 1997; Nowak and Miczyński, 2002; Tian et al. 2007; Petri and Scorza 2010). In the first rooting protocol for the Polish plum cultivar 'Węgierka Zwykła', the highest rooting rate, reaching $86.4 \%$, was obtained with high concentrations of exogenous auxins applied to the culture medium: $25.54 \mu \mathrm{M}$ IAA and $9.84 \mu \mathrm{M}$ IBA (Małodobry 1986). We decided to repeat the procedure as a control treatment, however, it occurred to be far less effective for our WZ clone (rooting rate $33.3 \%$ ). The second examined cultivar, 'Wegierka Dąbrowicka', exhibited a higher rooting ability under conditions applied. It supports the opinion that rhizogenic potential in the common plum is strongly genotype-dependent. The most frequently repeated procedure of Gonzales Padilla et al. (2003) generates a broad range of results, depending on the genotype subjected to rooting, from merely $20 \%$ of rooted shoots in 'Improved French' (Petri and Scorza 2010), $78 \%$ in 'President' (Tian et al. 2007), to $91 \%$ in 'Stanley' (Gonzales Padilla et al. 2003).

Our study was designed to replace exogenous auxins added to the rooting medium with phytoactive organic supplements. Therefore, in supplemented media the level
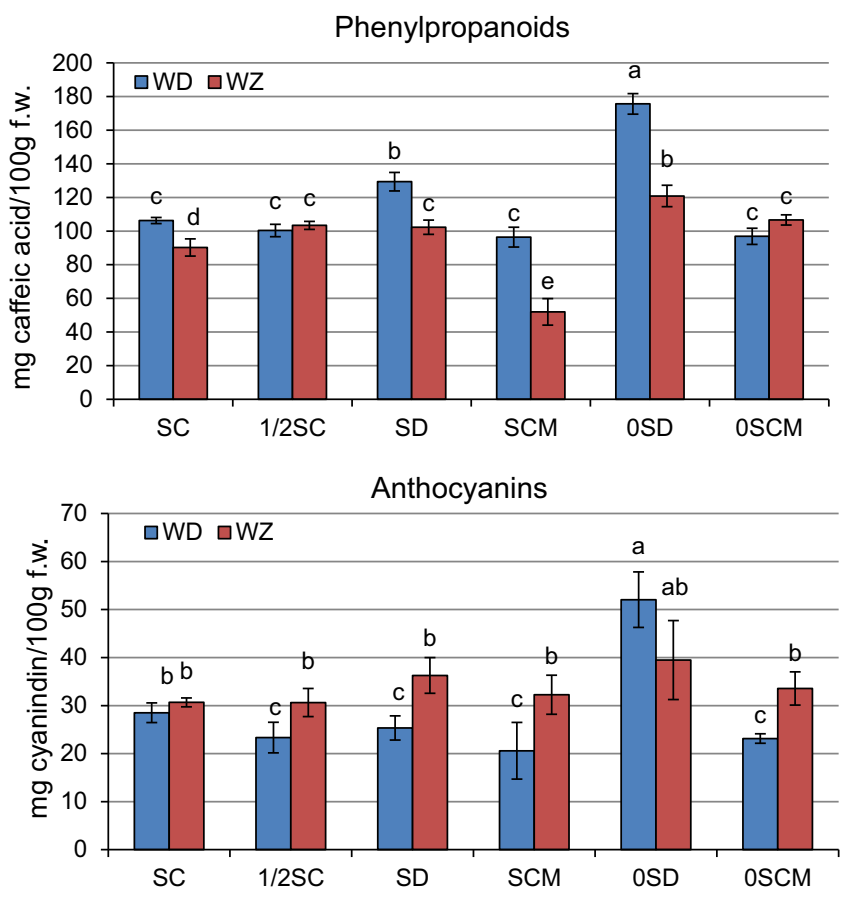

to two-way ANOVA and post hoc Duncan test at $P<0.05$. Abbreviations SC, 1/2SC, SD, SCM, OSD, OSCM are codes of different root induction media (see "Materials and methods" and Table 1 for a description)

of exogenous auxins was reduced by half in comparison with the control medium. In WZ cultivar the rooting percentage on supplemented media with reduced auxin content was the same as in the control medium. Interestingly, on the non-supplemented medium with a reduced auxin content, used here as an additional control, the rooting percentage decreased. Moreover, some of WZ shoots produced roots on the medium without exogenous auxins and containing only algal conditioned medium. In the light of our results, WZ plum can be regarded as a recalcitrant and difficult-to-root genotype, which requires intensive exogenous stimulation to develop adventitious roots. It is encouraging that such a stimulation can also be evoked by natural phytoactive supplements, allowing to reduce the content of exogenous auxins in the rooting treatment.

Adventitious root formation in 'Węgierka Dąbrowicka' required lower doses of exogenous auxins than in 'Węgierka Zwykła'. The higher auxin level applied in the control treatment significantly reduced the rootability of shoots, which, however, remained satisfactory. Unlike in WZ, phytoactive supplements in WD inhibited adventitious rooting. The decrease in the rooting percentage was especially pronounced in the presence of the algal conditioned medium. This decline could be attributed to stressful conditions induced by the exogenous application of specific natural products to the culture medium. Natural products 

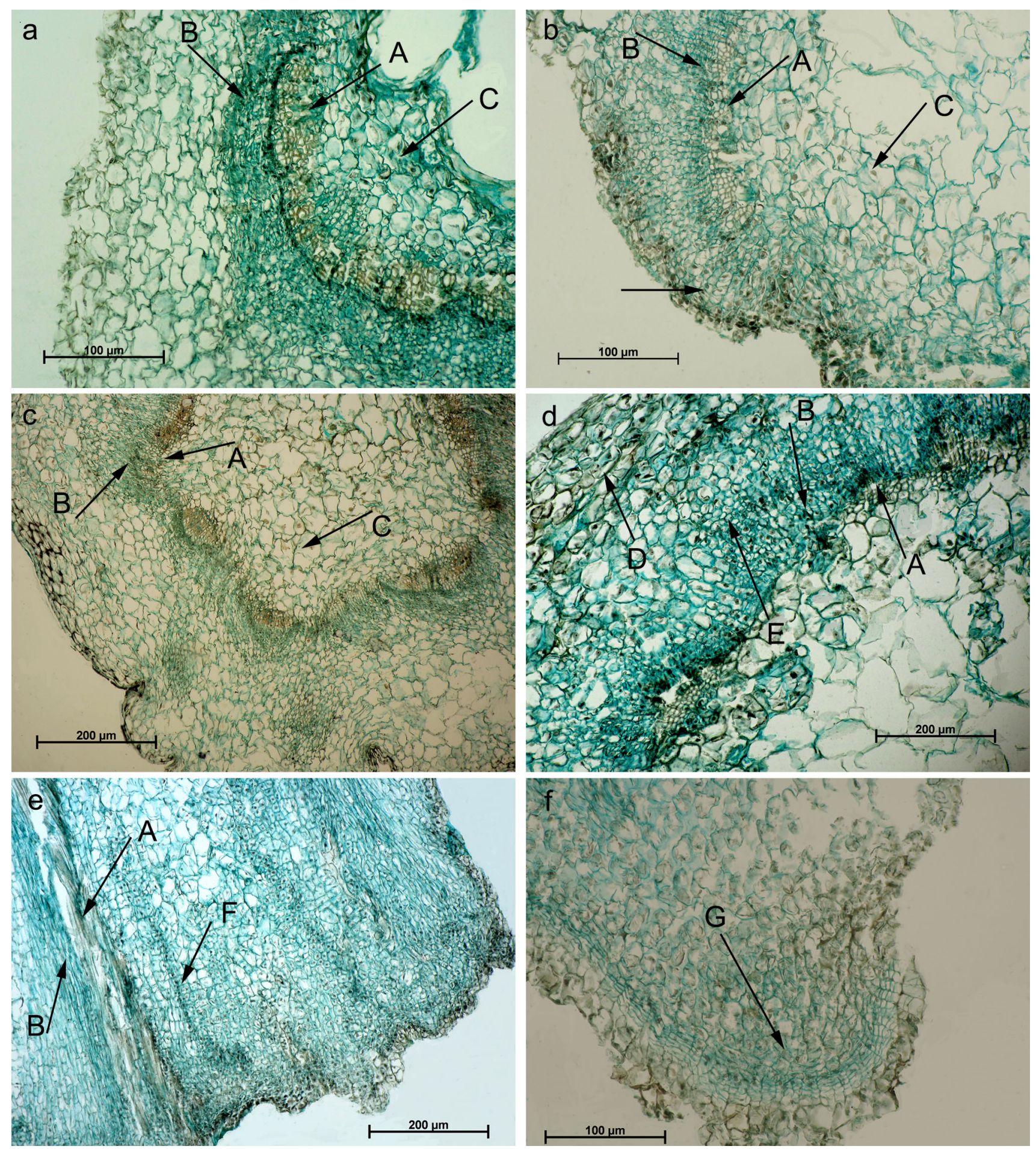

Fig. 4 Dedifferentiation regions in Prunus domestica L. microshoots after $5(\mathbf{a}, \mathbf{b})$ and $7(\mathbf{c}-\mathbf{f})$ days of root induction phase. a, b, f 'Węgierka Dąbrowicka' and c, d, e 'Węgierka Zwykła'. Arrows: $A$ xylem, $B$ phloem, $C$ core cells with big nuclei, $D$ divisions in

may contain non-growth promoting compounds, such as abscisic acid, inhibitors of gibberellin synthesis or ethylene inactivators, which can enhance stress (Ragonezi et al. subepidermal layer, $E$ phloem-derived meristematic centers, $F$ dividing core cells along xylem, $G$ tangentially dividing cells on the cutting edge

2010; Stirk et al. 2014). On the other hand, stress encountered during early stages of adventitious rhizogenesis may lead to reprogramming of cells making them 

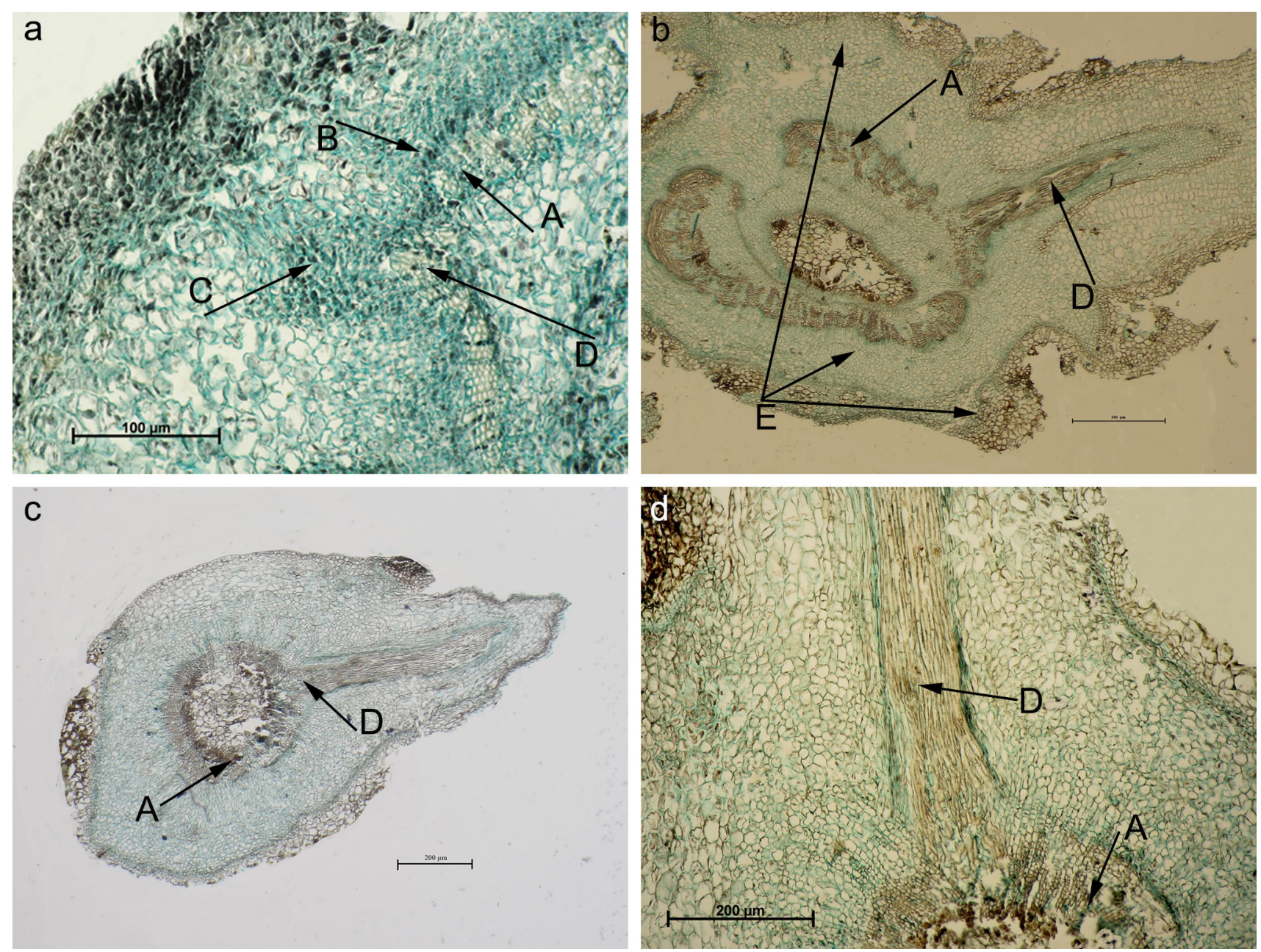

Fig. 5 Emergence of adventitious roots in Prunus domestica L. microshoots after 5 (a) and 7 (b-d) days of root induction phase. Arrows: $A$ xylem, $B$ phloem, $C$ phloem-derived meristematic centers, $D$ longitudal section of vessels, $E$ callus-forming cells

Table 3 Carbohydrates determined in dialyzed pineapple pulp using HPLC analysis

\begin{tabular}{lrll}
\hline Carbohydrates & $\mathrm{mg} / \mathrm{ml}$ & Carbohydrates & $\mathrm{mg} / \mathrm{ml}$ \\
\hline Fructose & 16.51 & Sucrose & 0.32 \\
Glucose & 16.51 & Iso-maltotriose & 0.13 \\
Maltose & 1.42 & Trehalose & 0.002 \\
Kestose & 0.37 & & \\
\hline
\end{tabular}

competent to respond to rooting stimuli (da Costa et al. 2013). Such mechanism may explain rhizogenic ability in WD shoots induced on auxin-free media.

Considering the root-promoting character of supplements tested, our previous studies revealed that natural auxins are not likely to be present in dialyzed pineapple (Wiszniewska et al. 2013). Their presence in the conditioned medium obtained from green alga Desmodesmus subspicatus has not been confirmed either. The root- promoting effect of dialyzed pineapple can be attributed to the presence of carbohydrates. Total soluble sugars constituted $4.2 \%$ f.w. of pineapple dialyzate, and these were predominantly glucose, fructose and maltose. Since adventitious root formation is an energy-requiring process, an additional supply of carbohydrates may intensify root development (Li and Leung 2000; Takahashi et al. 2003). In Eucalytus glucose supplementation during the root induction stage improved rooting efficiency under suboptimal auxin concentration (da Rocha Correa et al. 2005). The same relationship was observed in the recent study on WZ shoots rooted in a supplemented media. The regulatory and antioxidative role of some sugars cannot be excluded either (da Rocha Correa et al. 2005; Ahkami et al. 2008; Agulló-Antón et al. 2011; Denaxa et al. 2012; Peshev et al. 2013).

Certain wounding-related compounds, especially phenolics, exhibit root-promoting activity (De Klerk et al. 1999, 2011). In fact, in pineapple dialyzate we have 
Table 4 Phenolic acids determined in pineapple dialyzate using UHPLC analysis

Fig. 6 HPLC chromatograms of algal conditioned medium tested for the presence of phenolic acids

\begin{tabular}{lcllll}
\hline Phenolic acids & $\mu \mathrm{g} / \mathrm{ml}$ & & Phenolic acids & $\mu \mathrm{g} / \mathrm{ml}$ & \\
\hline Homovanillic acid & 11.2 & Monophenol & Ferulic acid & 0.29 & Diphenol \\
Vanillic acid & 4.49 & Monophenol & $p$-Hydroxobenzoic acid & 0.19 & Monophenol \\
Cinnamic acid & 4.47 & Precursor & Rosmarinic acid & 0.19 & Polyphenol \\
Syringic acid & 0.91 & Monophenol & Chlorogenic acid & 0.05 & Polyphenol \\
Sinapic acid & 0.82 & Monophenol & Gallic acid & 0.02 & Triphenol \\
Caffeic acid & 0.68 & Diphenol & 3,4-Dihydroxobenzoic acid & 0.01 & Diphenol \\
Benzoic acid & 0.64 & Precursor & Salicylic acid & 0.008 & Monophenol \\
Coumaric acid & 0.62 & Monophenol & Gentisic acid & 0.0005 & Diphenol \\
\hline
\end{tabular}
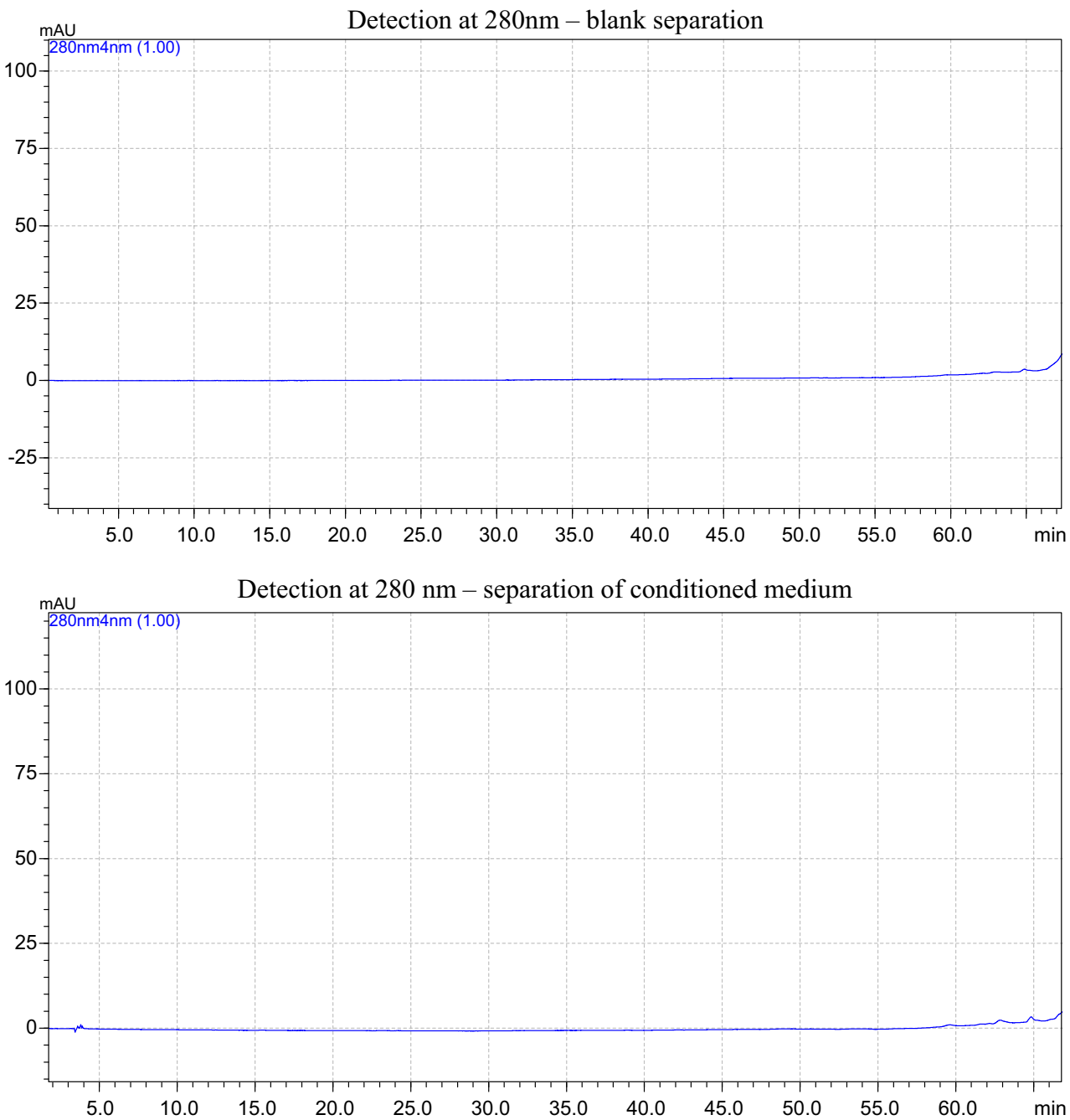

determined sixteen phenolic acids that could promote rhizogenesis in WZ plum cultivar. Some of phenolic acids, such as ferulic, gallic and chlorogenic acid were reported to stimulate rooting in Malus domestica (De Klerk et al. 2011). The pineapple dialyzate could be regarded as a source of antioxidants, mainly phenolic acids, which are known to counteract the auxin oxidation and inactivation (De Klerk et al. 2011).
The root-promoting character of algal conditioned medium is more difficult to explain. Rooting of plum in the presence of CM was effective only in difficult-to-root WZ cultivar, while in responding WD the rooting was inhibited. This important difference may be attributed to a genotypedependent reaction. We have reported a rhizogenic activity of this supplement in woody Daphne cultures (Wiszniewska et al. 2013). In the plum rooting treatment we have 
applied $10 \%(\mathrm{v} / \mathrm{v})$ of $\mathrm{CM}$ into the culture medium, while in Daphne better results with $20 \%(\mathrm{v} / \mathrm{v})$ of CM (Wiszniewska et al. 2013). In the plum we have tested the suitability of $\mathrm{CM}$ at a lower concentration, since our previous studies revealed that the excessive concentration of $\mathrm{CM}$ in the culture medium deteriorates both proliferation of cells in cell suspension and organogenesis in shoot culture (Hanus-Fajerska et al. 2009; Wiszniewska et al. 2013). Taking into account diverse reactions of plum cultivars, the reduction in $\mathrm{CM}$ concentration to $10 \%$ seemed substantiated. Complete chemical composition of CM has still to be revealed. We have found that carbohydrates are present in trace amounts, and phenolic acids are absent. This may partially explain differences in root-promoting activity between the conditioned medium and pineapple dialyzate in WD plum. Reaction of WZ cultivar to $\mathrm{CM}$ application could be attributed either to stressful conditions generated by algal exudates or to the activity of an unknown auxinlike compound. It has been also reported that cultured $D$. subspicatus cells are able to secrete bioactive low-molecular-weight compounds related to peptides or glycopeptides (Grabski et al. 2010). However, the hypotheses require verification during further studies on $\mathrm{CM}$ composition.

Endogenous phenolic compounds are considered as markers of a well-defined physiological state favorable to adventitious rooting (Curir et al. 1990; De Klerk et al. 1999). For instance, flavonoids (flavonols and anthocyanins) are known as inhibitors of auxin transport (Rusak et al. 2010). In this respect, the differences in flavonoid content detected yet before the root induction between WZ and WD could affect the response of the shoots to the rooting treatment. After root induction the accumulation of various phenolic compounds was stimulated in all treatments. Interestingly, the examined supplements had a greater impact on the accumulation than the level of exogenous auxins. In both cultivars the highest accumulation of phenolic compounds occurred in the dialyzatesupplemented auxin-free medium, with no relation to shoot rootability. This could be a result of processes other than rhizogenesis, for example defense reactions against stress influenced by the presence of natural supplements. High content of anthocyanins in WZ indicates on higher sensitivity of this cultivar to stressful environment during rooting induction, especially in relation to light conditions (Merzlyak and Chivkunova 2000).

Promoted accumulation of total phenolics, phenylpropanoids and flavonols in WD in the presence of phytoactive supplements can be related to its higher response to rooting treatments. Reduced biosynthesis of phenylpropanoid derivatives, such as phenolic acids and lignin, often inhibits cell division and differentiation process (Santos Macedo et al. 2012). On the other hand, this is the evidence that in woody plants high levels of endogenous flavonoids (flavonols and anthocyanins) are linked with the rooting ability (Curir et al. 1990; Fu et al. 2011).

Considering root development, we have distinguished three regions of mitotic activity as a consequence of dedifferentiation of the cultivated shoots. The most active abundant divisions occurred near the phloem and may result in the formation of meristematic centers that later gave rise to new roots. All developed roots, regardless of the medium on which they were induced and the way of formation (with callus and without callus) originated from the division region within the phloem tissue. In in vitro cultivated shoots of Malus, Alnus, Castanea and Cedrela the initial meristemoids of adventitious roots develop either within the phloem adjacent to cambium, at ray parenchyma or cortical and phloem parenchyma (Zhou et al. 1992; Goncalves et al. 1998; Naija et al. 2008; Millán-Orozco et al. 2011; San José et al. 2012). Mitotic activity is also observed within the core. Depending on the species, time required for root-initiating meristematic activity in response to inductive treatment is $2-8$ days, although roots emerge a few days later and their induction is not synchronous. It seems that in the case of Prunus domestica the mitotic activity within the subepidermal layer and core parenchyma can result in callus formation only. The asynchronous mode of root induction and development in plum hampers drawing an exact conclusion on the relationship between rootability and the effect of exogenous compounds applied in the culture medium. This also supports the finding that the examined plum cultivars have individual rates of root induction and development.

To conclude, plum genotypes contrasting in their rooting response will be a valuable plant material in further studies on adventitious root formation in Prunus domestica. Importantly, during rooting of the difficult-to-root plum cultivar under reduced level of exogenous auxins, the presence of phytoactive supplements positively affected the rooting frequency. A decrease in the level of exogenous auxins required for rooting has a practical significance especially for commercial tissue culture laboratories, since it can limit the losses caused by the poor quality of the root system. A lower level of auxins applied in the rooting protocol minimizes the risk of inhibitory effect of auxins on the shoot growth. Moreover, the substitution of exogenous auxins with natural rooting stimulators may facilitate plant production in organic agriculture systems. Compounds present in natural products tested here seem to enhance rhizogenic reactions in woody species poorly responding to rooting treatments. The increasing restrictions on the use of chemicals in crop production reflect the need for developing efficient methods for non-chemical plant growth regulation (Hansen and Petersen 2004). In this respect the approach presented herein can be a promising 
alternative for in vitro rooting. Further analyses of rootingrelated markers in the common plum should give an insight into the biochemical response during root induction in easy- and difficult-to-root genotypes of Prunus domestica, as well as into the mode of action of phytoactive medium supplements in rooting treatments.

Acknowledgements This research was financed by Ministry of Science and Higher Education of Republic of Poland (DS 3500).

Author contribution AW planned and designed all experiments, performed in vitro rooting experiments, performed analyzes of phenolic profile, collected and analyzed data, wrote manuscript, prepared figures and tables; BN maintained stock cultures of plant material, performed in vitro rooting experiments, performed anatomical studies, collected data, contributed to manuscript writing; AK performed analyzes of peroxidase activity and phenolic profile, collected data, contributed to manuscript writing; ES performed anatomical studies, contributed to manuscript writing; KG produced conditioned medium and pineapple dialyzate, contributed to manuscript writing; MD performed analyzes of carbohydrate profile and phenolic acid profile in pineapple dialyzate, collected data; O D-G performed analysis of phenolic acid content in conditioned medium, collected data; KD collected and analyzed data on carbohydrate profile and phenolic acid profile in pineapple dialyzate; ZT invented the way of algal conditioned medium production.

Open Access This article is distributed under the terms of the Creative Commons Attribution 4.0 International License (http://crea tivecommons.org/licenses/by/4.0/), which permits unrestricted use, distribution, and reproduction in any medium, provided you give appropriate credit to the original author(s) and the source, provide a link to the Creative Commons license, and indicate if changes were made.

\section{References}

Agulló-Antón MÁ, Sánchez-Bravo J, Acosta M, Druege U (2011) Auxins or sugars: what makes the difference in the adventitious rooting of stored carnation cuttings? J Plant Growth Regul 30(1):100-113

Ahkami AH, Lischewski S, Haensch K-T, Porfirova S, Hofmann J, Rolletschek H, Melzer M, Franken P, Hause B, Druege U, Hajirezaei MR (2008) Molecular physiology of adventitious root formation in Petunia hybrida cuttings: involvement of wound response and primary metabolism. New Phytol 181:613-625

Al-Khayri JM (2011) Influence of yeast extract and casein hydrolysate on callus multiplication and somatic embryogenesis of date palm (Phoenix dactylifera L.). Sci Hort 130:531-535

Amin GH, Al-Gendy AA, El-Ayouty YM, Abdel-Motteleb A (2009) Effect of Spirulina platensis extract on growth, phenolic compounds and antioxidant activities of Sisymbrium irio callus and cell suspension cultures. Aust J Basic Appl Sci 3:2097-2110

Arthur GD, Stirk WA, Van Staden J (2004) Screening of aqueous extracts from agar and gerlite for root-stimulating activity. S Afr J Bot 70:595-601

Auderset G, Moncousin C, O'Rourke J, Morre DJ (1997) Stimulation of root formation in difficult-to-root woody cuttings by dithiothreitol. Int J Plant Sci 158:132-135

Curir P, van Sumere CF, Termini A, Barthe P, Marchesini A, Dolci M (1990) Flavonoid accumulation is correlated with adventitious roots formation in Eucalyptus gunnii Hook micropropagated through axillary bud stimulation. Plant Physiol 92:1148-1153

da Costa CT, de Almeida MR, Ruedell CM, Schwambach J, Maraschin FS, Fett-Neto AG (2013) When stress and development go hand in hand: main hormonal controls of adventitious rooting in cuttings. Front Plant Sci 4(113):1-19

da Rocha Correa L, Paim DC, Schwambach J, Fett-Neto AG (2005) Carbohydrates as regulatory factors on the rooting of Eucalyptus saligna Smith and Eucalyptus globulus Labill. Plant Growth Regul 45(1):63-73

Davies FT, Davis TD, Kester DE (1994) Commercial importance of adventitious rooting to horticulture. In: Davis TD, Haissig BE (eds) Biology of adventitious root formation. Plenum Press, New York, pp 53-59

De Klerk G-J, van der Krieken W, De Jong JC (1999) The formation of adventitious roots: new concepts, new possibilities. In Vitro Cell Dev Biol Plant 35:189-199

De Klerk G-J, Guan H, Huisman P, Marinova S (2011) Effects of phenolic compounds on adventitious root formation and oxidative decarboxylation of applied indoleacetic acid in Malus 'Jork 9'. Plant Growth Regul 63:175-185

Denaxa NK, Vemmos SN, Roussos PA (2012) The role of endogenous carbohydrates and seasonal variation in rooting ability of cuttings of an easy and a hard to root olive cultivars (Olea europaea L.). Sci Hort 143:19-28

Filutowicz A, Kużdowicz A (1951) Plant microtechnics. PWRiL, Warsaw (in Polish)

Fu Z, Xu P, He S, Jaime A (2011) Dynamic changes in enzyme activities and phenolic content during in vitro rooting of tree peony (Paeonia suffruticosa Andr.) plantlets. Maejo Int J Sci Technol 5(02):252-265

Fukumoto L, Mazza G (2000) Assessing antioxidant and prooxidant activities of phenolic compounds. J Agric Food Chem 48(8): 3597-3604

Goncalves JC, Giogo G, Amancio S (1998) In vitro propagation of chestnut (Castanea sativa $\times C$. crenata): effects of rooting treatments on plant survival, peroxidise activity and anatomical changes during adventitious root formation. Sci Hort 72:265-275

Gonzales Padilla IM, Webb K, Scorza R (2003) Early antibiotic selection and efficient rooting and acclimatization improve the production of transgenic plum plants (Prunus domestica L.). Plant Cell Rep 22:38-45

Grabski K, Tukaj Z (2008) Autoinduction activity of conditioned medium obtained from high density cultures of green alga Scenedesmus subspicatus. J Appl Phycol 20:323-330

Grabski K, Aksmann A, Mucha P, Tukaj Z (2010) Conditioned medium factor produced and released by Desmodesmus subspicatus and its effect on cell cycle of the producer. J Appl Phycol 22:517-524

Hansen CW, Petersen KK (2004) Development of new alternative methods for plant growth regulation in Europe. Proc Plant Growth Reg Soc Am 31:13-14

Hanus-Fajerska E, Czura A, Grabski K, Tukaj Z (2009) The effect of conditioned medium obtained from Scenedesmus subspicatus on suspension culture of Silene vulgaris (Caryophyllaceae). Acta Physiol Plant 31:881-887

Hou J, Guo S, Wang G (2010) Effects of in vitro subculture on the physiological characteristics of adventitious root formation in microshoots of Castanea mollissima cv. 'yanshanhong'. J For Res 21:155-160

Kakani A, Li G, Peng Z (2009) Role of AUX1 in the control of organ identity during in vitro organogenesis and in mediating tissue specific auxin and cytokinin interaction in Arabidopsis. Planta 229:645-657

Kalinina A, Brown DCW (2007) Micropropagation of ornamental Prunus spp. and GF305 peach, a Prunus viral indicator. Plant Cell Rep 26:927-935 
Kaur S, Bhutani KK (2012) Organic growth supplement stimulants for in vitro multiplication of Cymbidium pendulum (Roxb.) Sw. Hort Sci (Praque) 39:47-52

Kitsaki CK, Zygouraki S, Ziobora M, Kintzios S (2004) In vitro germination, protocorm formation and plantlet development of mature versus immature seeds from several Ophrys species (Orchidaceae). Plant Cell Rep 23:284-290

Leva A (2011) Innovative protocol for "ex vitro rooting" on olive micropropagation. Cent Eur J Biol 6:352-358

Li M, Leung DWM (2000) Starch accumulation is associated with adventitious root formation in hypocotyl cuttings of Pinus radiata. J Plant Growth Regul 19:423-428

Lloyd G, McCown B (1981) Commercially-feasible micropropagation of mountain laurel, Kalmia latifolia, by use of shoot tip culture. Comb Proc Intl Plant Prop Soc 30:421-427

Małodobry A (1986) Micropropagation of 'Węgierka Zwykła' plum. Doctoral Thesis, University of Agriculture in Kraków, Poland (in Polish)

McDonald MS, Wynne J (2003) Adventitious root formation in woody tissue: peroxidase-a predictive marker of root induction in Betula pendula. In Vitro Cell Dev Biol Plant 39:234-235

Merzlyak MN, Chivkunova OB (2000) Light-stress-induced pigment changes and evidence for anthocyanin photoprotection in apples. J Photochem Photobiol B 55(2):155-163

Millán-Orozco L, Corredoira E, San José MC (2011) In vitro rhizogenesis: histoanatomy of Cedrela odorata (Meliaceae) microcuttings. Rev Biol Trop 59(1):447-453

Molnar Z, Ördög V (2005) The effect of cyanobacterial compounds on the organogenesis of pea cultured in vitro. Acta Biol Szeged 49(1-2):37-38

Montero-Calasanz MC, Santamaría C, Albareda M, Daza A, Duan J, Glick BR, Camacho M (2013) Alternative rooting induction of semi-hardwood olive cuttings by several auxin-producing bacteria for organic agriculture systems. Span J Agric Res 11(1): $146-154$

Murashige T, Skoog F (1962) A revised medium for rapid growth and bioassay with tobacco tissue cultures. Physiol Plant 15:473-497

Naija S, Elloumi N, Jbir N, Ammar S, Kevers C (2008) Anatomical and biochemical changes during adventitious rooting of apple rootstocks MM 106 cultured in vitro. C R Biol 331:518-525

Neumann K-H, Kumar A, Imani J (2009) Plant cell and tissue culture-a tool in biotechnology. Springer-Verlag, Berlin Heidelberg

Nowak B, Miczyński K (1997) Regeneration of plum (Prunus domestica L.) cultivars Čačanska Rodna, Stanley and Čačanska Najbolia from in vitro leaf explants. Folia Hort 9:33-42

Nowak B, Miczyński K (2002) The course and efficiency of organogenesis on leaf explants of plum 'Węgierka Zwykła' (Prunus domestica L.) induced by cytokinins. Electron J Pol Agric Univ Biotech 5(1). http://www.ejpau.media.pl/volume5/ issue $1 /$ biotechnology/art-02.html

Okunlola AI, Ofuya TI (2013) Effect of mixed cropping and plant extracts on the growth, yield and pest control of jute (Corchorus olitorius L.). Folia Hort 25:49-60

Pacholczak A, Szydło W, Jacygrad E, Federowicz M (2012a) Effect of auxins and the biostimulator Algaminoplant on rhizogenesis in stem cuttings of two dogwood cultivars (Cornus alba 'Aurea' and 'Elegantissima'). Acta Sci Pol Hortorum Cultus 11(2): 93-103

Pacholczak A, Szydło W, Zagórska K, Petelewicz P (2012b) The effect of biopreparations on the rooting of stem cuttings in Cotinus coggygria 'Young Lady'. Ann Warsaw Univ Life Sci SGGW Horticult Landsc Architect 33:33-41
Peshev D, Vergauwen R, Moglia A, Hideg É, Van den Ende W (2013) Towards understanding vacuolar antioxidant mechanisms: a role for fructans? J Exp Bot 64(4):1025-1038

Petri C, Scorza R (2010) Factors affecting adventitious regeneration from in vitro leaf explants of 'Improved French' plum, the most important dried plum cultivar in the USA. Ann Appl Biol 156:79-89

Pociecha E, Dziurka M (2015) Trichoderma interferes with cold acclimation by lowering soluble sugars accumulation resulting in reduced pink snow mould (Microdochium nivale) resistance of winter rye. Environ Exp Bot 109:193-200

Ragonezi C, Klimaszewska K, Castro MR, Lima M, de Oliveira P, Zavattieri MA (2010) Adventitious rooting of conifers: influence of physical and chemical factors. Trees 24(6):975-992

Rusak G, Cerni S, Polancec DS, Ludwig-Müller J (2010) The responsiveness of the IAA2 promoter to IAA and IBA is differentially affected in Arabidopsis roots and shoots by flavonoids. Biol Plant 54(3):403-414

San José MC, Romero L, Janeiro LV (2012) Effect of indole-3butyric acid on root formation in Alnus glutinosa microcuttings. Silva Fennica 46(5):643-654

Santos Macedo E, Sircar D, Cardoso HG, Peixe A, Arnholdt-Schmitt B (2012) Involvement of alternative oxidase (AOX) in adventitious rooting of Olea europaea L. microshoots is linked to adaptive phenylpropanoid and lignin metabolism. Plant Cell Rep 31(9):1581-1590

Sarropoulou V, Dimassi-Theriou K, Therios I (2013) Effects of exogenous L-arginine on in vitro rooting, chlorophyll, carbohydrate, and proline concentrations in the sweet cherry rootstock M $\times$ M 14 (Prunus avium L. $\times$ Prunus mahaleb L.). Plant Biotech Rep 7:457-465

Saxena S, Pandey AK (2001) Microbial metabolites as eco-friendly agrochemicals for the next millennium. Appl Microbiol Biotechnol 55(4):395-403

Serna M, Hernandez F, Coll F, Coll Y, Amoros A (2012) Brassinosteroid analogues effects on the yield and quality parameters of greenhouse-grown pepper (Capsicum annuum L.). Plant Growth Regul 68:333-342

Štefančič M, Štampar F, Osterc G (2005) Influence of IAA and IBA on root development and quality of Prunus 'GiSelA 5' leafy cuttings. HortScience 40:2052-2055

Stirk WA, Tarkowska D, Turecova V, Strnad M, van Staden J (2014) Abscisic acid, gibberellins and brassinosteroids in Kelpak ${ }^{\circledR}$, a commercial seaweed extract made from Ecklonia maxima. J Appl Phycol 26:561-567

Takahashi F, Sato-Nara K, Kobayashi K, Suzuki M, Suzuki H (2003) Sugar-induced adventitious roots in Arabidopsis seedlings. J Plant Res 116:83-91

Tereso S, Miguel CM, Mascarenhas M, Roque A, Trindade H, Maroco J, Oliveira MM (2008) Improved in vitro rooting of Prunus dulcis Mill. cultivars. Biol Plant 52:437-444

Tian L, Sibbald S, Subramanian J, Svircev A (2007) Characterization of Prunus domestica L. in vitro regeneration via hypocotyls. Sci Hort 112:462-466

Wiszniewska A, Hanus-Fajerska E, Grabski K, Tukaj Z (2013) Promoting effects of organic medium supplements on the micropropagation of promising ornamental Daphne species (Thymelaeaceae). In Vitro Cell Dev Biol Plant 49:51-59

Zhou J, Wu H, Collet GF (1992) Histological study of initiation and development in vitro of adventitious roots in minicuttings of apple rootstocks of M26 and EMLA 9. Physiol Plant 84:433-444 